\title{
Homenaje a Paul Rivet
}

por Jorge C. Muelle

\section{Señores:}

Este es un homenaje a Paul Rivet.

Y puesto que no es mi deseo que este homenaje sea un vano amontonamiento de adjetivos; puesto que no deseo que parezca el juicio apasionado de un admirodor y de un amigo, hubiera querido examinar aquí su obra de antropólogo con objetividad y método, en la forma en que Rivet que como todo buen francés llevaba en sí el sentido de la dignidad de la razón, aceptaría ser juzgado.

Pero este esfuerzo maiha resultado inútil por lo vasta y copiosa que he encontrado la obra de Rivet. He de confesar que creía conocerla y he descubierto al tratar de cumplir el honroso encargo que me ha traído hoy a ocupar esta tribuna, que aunque no podemos decir que nos es desconocida, debemos admitir que nos es poco conocida en su integridad y profundidad, y que su labor merece un sereno y detenido examen que va más allá de mis recursos y del tiempo que disponía antes de presentarme a ustedes, tiempo y recursos que he empleado únicamente en coleccionar los títulos de su bibliografía. Me pregunto ahora cómo pudo hacer este hombre extraordinario para cultivar la investigación científica al mismo tiempo que atendía a las tareas administrativas de director de uno de los museos más importantes de Francia, al mismo tiempo que doblaba su actividad de Concejal de París, que co-

* Discurso de orden pronunciado en el homenaje que la Facultad de Letras tributó en el presente año al insigne antropólogo francés. 
mo diputado por el Sena defendía en la Asamblea Nacional sus ideas y sus proyectos, al mismo tiempo que redoblaba su actividad de fundador de un partido político, que cumplía una misión, realizaba repetidos viajes y presidía numerosas instituciones y conferencias.

La enorme actividad de Rivet que sólo una gran vitalidad como la suya pudo cumplir, está jalonada por los títulos de'su producción intelectual que hasta la víspera de su muerte, acaecida el 21 de marzo de este año, buscó la verdad serenamente, dignamente, justiciera e inteligentemente, y puso orden y medida en los temas que trató.

Fué en 1903 que presentó a la Sociedad de Americanistas de París su Estudio sobre los indios de la región de Riobamba. En 1905, el Journal de la Societé des Américanistes publicaba Los indios Colorados; en 1906, el mismo Journal, Cinco años de estudios antropológicos en el Ecuador, y en 1907, L' Antropologie, la primera parte de su monografía sobre Los indios Jíbaros. Así comenzó su carrera de americanista, que en los terrenos de la etnología, la geografía, la historia, la antropología y la lingüística floreciera, diera tan maduros frutos y dejara la semilla de un ejemplo de laboriosidad y acuciosa observación.

Charles Marie de la Condamine fué su inspiración y modelo. Enviado tras sus huellas con la Misión del Servicio Geográfico del Ejército que dirigía el generaPourgebois y que vinoatambién al Ecuador a medir un gradormeridiamainellitenienter Rivet, de origen lorenés, distinguido alumno de L'Ecole du Service de Sanité Militaire de Lyon, había sido graduado doctor en medicina a precoz edad. La Condamine, al lado de su trabajo cartográfico, había recogido datos lingüísticos y etnográficos principalmente sobre los jíbaros y los omaguas; Rivet comprendió igualmente que la geografía es sólo un preludio a la antropología y que los estudios geográficos no estaban completos sino con la etnografía del lugar. Como médico, su misión lo llevaba al hombre, y su entrañable concepción del deber hizo que se consagrara con toda el alma a las tierras de - América.

Es en esta concepción del deber y en su cumplimiento a conciencia, que encuentro la raíz de su amor al indio americano: estudió con tanta devoción el tema que le fué confiado, que llegó a conocerlo bien, y por ello simpatizar con él y con él llegar a compenetrarse $e$ identificarse. 
El aborígen americano fué objeto de sus investigaciones desde todos los ángulos estrictamente científicos: antropológico, arqueológico, etnográfico y lingüístico. Sobre todo, su contribución a la lingǘstica americana debe ser recalcada en particular, y vamos a citar algunos títulos: "La lengua jíbaro o siwora"; "Afinidades de las lenguas del Sur de Colombia y del Norte del Ecuador (grupos Poniquita, Coconuco y Barbacoa)"; "La familia lingüística Capakura"; Los dialectos Pano de Bolivia"; "La familia Lapacu o Apolista": "La lengua Saraveka"; "La lengua Kanocana": "La lengua Mobina"; "Las lenguas del Purús, del Yurúa y de las regiones limitrotes"; en colaboración con el padre Tastevin éstas del grupo arawak, y con Crequi-Montfort las de Bolivia. Su conocimiento lingǘstico se expresa también de modo más general en "Las lenguas de los pueblos", tomo VII de la Encyclopedie Française, y la valiosa contribución "Las lenguas americanas" publicado en la serie de Meillet y Cohen sobre las lenguas del mundo.

Rivet no se contentaba con/el estudio platónico de un asunto, y así como sus investigaciones einológicas enriquecian con especímenes los museos, las lingüísticas aportaban libros y documentos a las bibliotecas. En esto, su cuidado rayaba en manía de coleccionista. Buena prueba es su colección de libros y folletos sobre el quechua que en hora feliz adquiriera la Biblioteca Nacional de Lima y que con tanta paciencia y constancia formara el profesor en el cursa de toda suf vida. Los cuatro Solúmenes de Biblio-

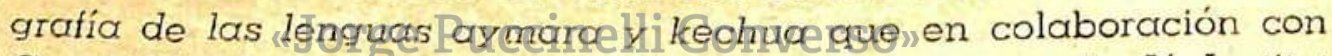
Crequi-Montfort publicara en Travaux et Memoires de L' Institut $D^{\prime}$ Ethnologie, son otra prueba de lo completas que fueron sus búsquedas. El Perú le debe además la publicación facsimilar de la crónica de Guamán Poma de Ayala.

Recuerdo que en una de sus varias visitas al Perú, Rivet, que recogía objetos de arte popular y cuanta cosa de algún interés etnográfico encontraba, vió a un chico jugando con un bolero - "Te lo compro"- le dijo, y lo compró. A las miradas de asombro de quienes lo acompañaban respondió: "Es para el Museo; ya no se juega en Francia y algún día no se jugará aquí tampoco".

A propósito de este juego favorito de Charles VII, es a Rivet que se debe el descubrimiento de su antigüedad. El conde Bégouen había excavado en Ariégo un objeto de grés; otro objeto similar de cuerno de reno había sido hallado en la gruta de Istu- 
ritz; la perspicacia de Rivet los comparó con objetos de forma parecida que tienen los esquimales de Tierra de Baffin y certificó así su uso $\mathrm{y}$ función (Interpretation ethnographique de deux objets prehistoriques, París 1924). Por supuesto que el bolero, boliche peruano, es de introducción española.

La arqueología americanc recibió de Rivet serios aportes. En 1923 publicó "La orfebrería precolombina de las Antillas, las Guayanas y Venezuela en sus relaciones con la orfebrería de otras regiones americanas". En 1946, con la colaboración de Arsandaux nos presentaba un libro fundamental: "Metalurgia Precolombina". Con el mismo Arsandaux y con Crequi-Montfort, había dado a luz "Contribución al estudio de la arqueología y de la metalurgia precolombina", en 1919, y con la colaboración de Verneau, en 1912, el primer tomo de "Etnografía antigua del Ecuador". La guerra estorbó la aparición del tomo II, y Rivet, que no podía ir a poner su libro al día sobre el terreno, se negó a publicarlo arguyendo que la arqueología sudamericana había, desde entonces, depasado sus daios: "Es an ejemplo de honestidad científica entre tantos ctros que honran su larga carrera" dice Raymond Ronze al comentar el caso.

El profesor Rivet coronó su abra de arqueólogo y etnógrafo al reorganizar en 1937 el viejo Museo de Etnografía del Trocadero, que con la ayuda de George-Henri Riviere y Jacques Soustelle se transformó en el actual Museo del Hombre. Ya el título denota una voluntad de opare? lbe cliencia Gaplalbance "del hombre común, "¿Por qué decir dolicocéfalo y braquicéfalo cuando podemos decir simplemente cabeza larga y cabeza ancha?" --comentaba Rivet-. Envió parte de su personal a los mejores museos del mundo para estudiar su funcionamiento, y el resultado fué ese modelo de organización del Palacio de Chaillot, en el que las colecciones están expuestas con simplicidad, método y maestría, en el que cada sección, cada vitrina constituye el resumen de muchos volúmenes puesto al alcance del hombre de la calle, y donde el conjunto es el mejor modelo de un museo didáctico; en el cual los mapas, leyendas y fotografias, juegan un papel tanto 0 más importante que los especimenes exhibidos. El tipo, color y tamaño de las leiras tienen particular efecto en los visitantes, guiándolos con seguridad. Y qué decir de los ficheros, inspirados en el sistema de Nordenskjold pero actualizados con talento; las tarjetas, de tamaño internacional, califican las colec- 
ciones por procedencia, materiales y numeración, haciendo rápida y práctica la consulta y facilitando la investigación. Verdaderamente, el Museo es la visualización de un curso sabio sobre los pueblos y hombres de la tierra toda, en su actualidad y su pasado.

Para completar los servicios del Museo del Hombre, Rivet, Secretario General del Instituto de Etnografía de la Universidad de París, consigue instalar a éste en el local de Chaillot, y allí reunió también el Instituto Francés de Antropología, la Sociedad Prehistórica y la Sociedad de Americanistas. Rivet murió ejerciendo la secretaría de la Sociedad de Americanistas, y esta circunstancia nos obliga a rendir el tributo que merece quien consagró su vida a América, anudando con lazos perdurables las relaciones entre su país y los nuestros.

El antropólogo que contribuía al estudio descriptivo y morfogénico de la curvatura femoral en el hombre y los antropoides, que estudiaban el prognatismo, que con la colaboración de Duckworth y Otto Schlaginhaufen presentara al XIV Congreso Internacional de Antropología su "Entente internacional para la unificación de las prácticas antropométricas sobre el vivo", tenía necesariamente que llevar su curiosidad a investigar los "Los Orígenes del hombre americano". La obra de este título que comienza con la publicación de un trabaio en Anthropos, otros en L'Anthropologie, y en Blilletin cae la SocietélEinguistique de París, en

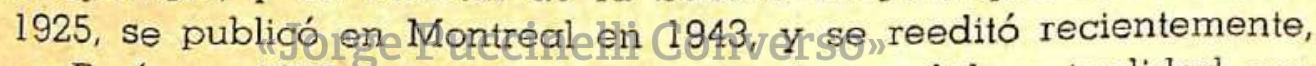
en París, en 1957, lo que indica que no ha perdido actualidad, por lo que traducido al castellano y al portugués constituye el gonfalón de la escuela que sostiene la teoría del origen oceániço del amerindio.

Los argumentos de Rivet, sin embargo, no son exclusivamente de carácter somático-ańtropológico sino que comprenden "las tres disciplinas", es decir incluyen testimonios etnológicos y lingüísticos. La llegada de australianos a la América del Sur está apoyada como era de esperarse, por argumentación lingüística.

La consistencia de las pruebas aportadas por Rivet ha merecido la consideración aun de sus opositores más encarnizados. Martínez del Río, un ecuánime antropólogo latinoamericano, ha dicho: "La alta personalidad científica del sabio francés y el número e importancia de sus aportaciones a la ciencia antropológica le hacen acreedor a que se le escuche con el mayor respeto". 
Los caracteres oceánicos de algunos pueblos de Sudamérica que señaló Rivet dirigen el problema hacia el área del Asja Meridional y, después de todo, como hace notar Raymond Furon, la doctrina clásica, que sitúa en el Asia oriental la cuna de los primeros inmigrantes americanos, no estaría muy alejada de la de Rivet. Pero aparte de esta consideración, la posición del profesor es constructiva en grado superlativo, pues obliga a sopesar hipótesis y razonamientos que quedarían marginados si nos dejásemos arrastrar por el entusiasmo de una teoría en boga.

La probidad de Rivet es aleccionadora al respecto. Cuando aquí en Lima un periodista que lo entrevistaba remarcó que el viaje que entonces Thor Heyerdal acababa de cumplir farvorecía sus teorías, Rivet respondió:

- Heyerdal ha probado que el viaje puede hacerse, pero no ha probado que se hizo en la prehistoria.

Se ha señalado la gran simpatía que Rivet sentía por la gente humilde, sea primitiva o parisiense, y esa es la verdad. Su vocación se debe quizás a la constatación que hizo en Sudiamérica de la existencia de una realidad infrahumana. Al sublimar su reacción, Rivet nos da otra lección y nos muestra que las actitudes emocionales deben ser superadas por el conocimiento: a ningún mal se le puede encontrar remedio si no se le conoce en su descarnada y objetiva redlidad. CRivet era un lontropólogo, y en todo antropólogo hay olgo de misionero converso"

Si el humanismo es la versión aristocrática de la antropología, la antropología es la versión democrática del humanismo. La definición de cultura como alquitaramiento, y la de historia como circunscrita al dominio político-militar y al acontecimiento cortesano, están hoy sobrepasadas. La gran revolución de nuestros tiempos surge de la constatación de que si hay pueblos sin historia y pueblos sin cultura eso se debe en gran parte a la parcial e imperfecta definición de cultura e historia que ha dominado el pensamiento de la época anterior al último tercio del siglo XIX. Para el intelectual de ahora no hay pueblos sin cultura -que es un acondicionamiento especial de la conducta-, como no hay grupo humano, por primitivo que sea, que no tome parte en ese proceso llamado Historia.

Es dentro del marco de estas ideas que debemos contemplar la obra cumplida por Rivet en la cátedra y fuera de ella. 
Cuando regresó a Francia en 1906, Rivet fué destacado al Muséum National d'Histoire Naturelle para trabajar con el material etnológico que aportaba. Fué nombrado después sucesivamente Asistente, Director Adjunto y Profesor de la cátedra de An. tropología, cargo que desde entonces implica la dirección del Mu. seo de Etnografía del Trocadero (Musée de l'Homme).

Sus condiciones de organizador han rebasado los límites de su patria: en Bogotá fundó el Instituto de Etnología de Colombia y sentó las bases para el Museo Nacional de esa vecina repúbli. ca; y en Méjico, con Coso y Torres-Bodet, creó el Instituto Francés de América Latina. Asimismo, había fundado en París con Paolo Duarte l'Institut de Hautes Etudes Bréstliennes, y contribuído a la fundación de la Maison de l'Amérique Latine y a l'Institut de Hautes Etudes de l'Améflque Latine de l'Université de Paris.

\section{Señores:}

Este es un homenaje a Paul Rivet, pero es también un homenaje a Francia porque Rivet es uno de sus hombres representativos. Rivet encarna la pasión en el hombre de pensamiento, de que nos habla Salvador de Modariaga; "lleva a la vida de la pasión su moderación, su sentido de la medida, que son las manifestaciones de un carácter construído sobre la razón": eso que ha hecho de Francia un pueblo que venza las crisis más difíciles de su historia con Jontroladoc lindepenclenciar "yoLibertad". "

* Título del último artículo de Rivet. 